\title{
Contribuição para a Formação de Psicólogos: Análise de Artigos de Carolina Bori Publicados Até 1962
}

Contributions To The Training Of Psychologists: Analyzing Carolina Bori's Articles Published

Until 1962

Contribuciones A La Formación De Los Psicólogos: Analise De Artículos De Carolina Bori Publicados Hasta 1962
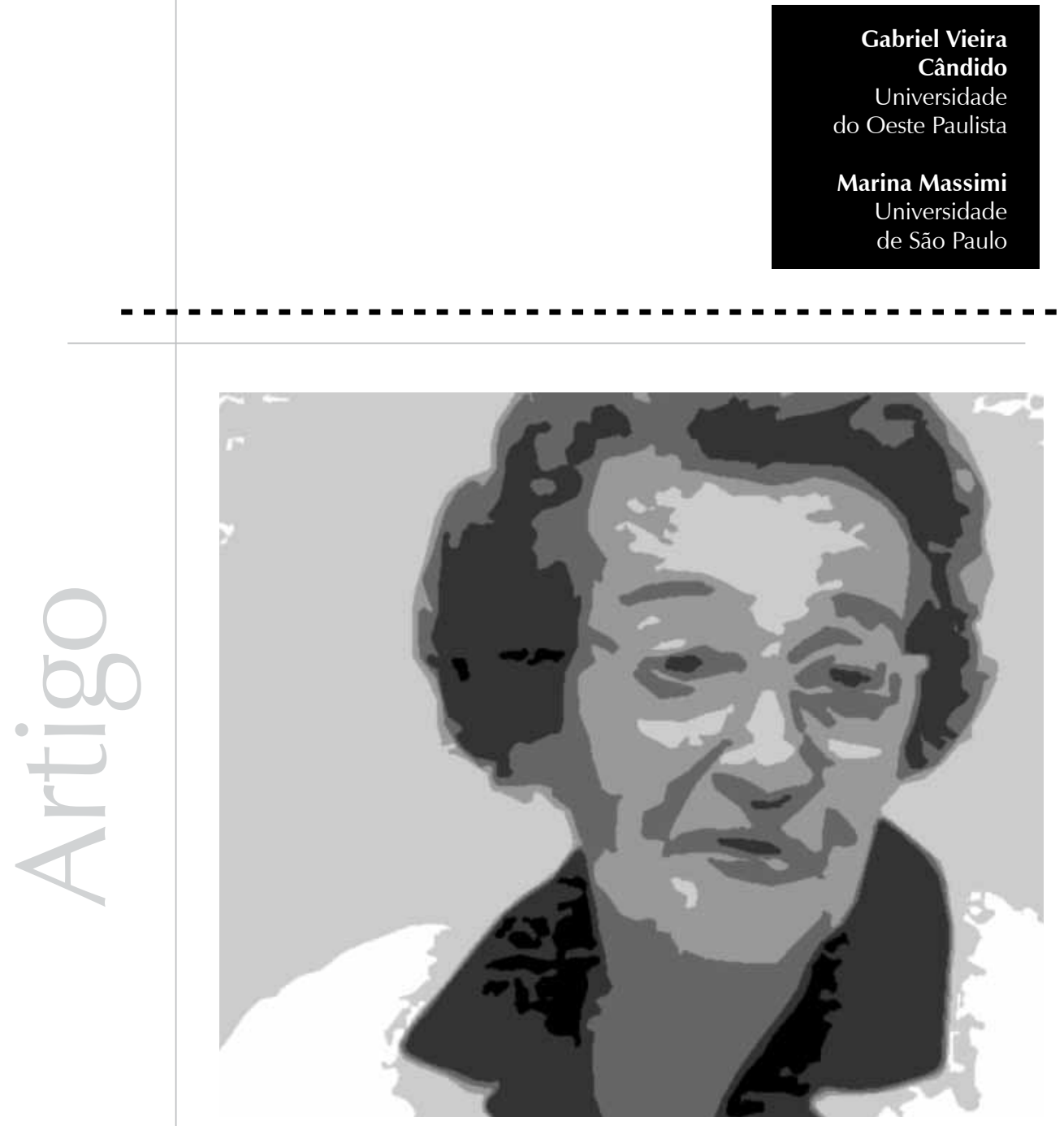
Resumo: A Psicologia, no Brasil, foi reconhecida legalmente no ano 1962. Contudo, antes desse ano, diversos profissionais já atuavam na área. Carolina Martuscelli Bori tem sido considerada um desses profissionais, e, dentre as contribuições que deu, sua luta para melhorar a formação profissional é uma das mais citadas. Com este trabalho, buscou-se conhecer sua contribuição a partir de artigos que Bori publicou até o ano 1962. A partir de uma busca feita nas revistas Ciência e Cultura, Boletim de Psicologia e Jornal Brasileiro de Psicologia, e no seu currículo Lattes, pela busca na biblioteca da Universidade de São Paulo e em referências de artigos escritos sobre a própria Carolina Bori, 19 artigos foram localizados, dos quais oito foram publicados até 1962. A análise feita permite afirmar que a obra de Carolina Bori apresenta discussões que podem auxiliar na elaboração e no direcionamento de várias questões éticas e acadêmicas atuais, como: a pesquisa experimental em cursos de graduação, a metodologia científica, o desenvolvimento científico e a produção do conhecimento.

Palavras-chave: História da Psicologia-Brasil. Pesquisa científica - Psicologia. Psicologia experimental. Fenômenos e processos psicológicos. Carolina Martuscelli Bori, 1924-2004

Abstract: Psychology in Brazil was legally recognized in 1962. However, before this year, many professionals have worked in this area. Carolina Martuscelli Bori has been considered one of those professionals and among the contributions she made, her efforts to ameliorate the professional training is one of the most cited. This article investigates Bori's contribution published until 1962. The search was made in the journals Ciência e Cultura, Boletim de Psicologia and Jornal Brasileiro de Psicologia and in her curriculum Lattes, in search for the library of the University of São Paulo and references of Carolina Bori's articles. Altogether, 19 articles were located, eight of which were published until 1962. The analysis allows us to state that the work of Carolina Bori presents discussions that may assist the design and targeting of various current ethical and academical issues, as experimental research in undergraduation courses, scientific methodology, scientific development and knowledge production.

Keywords: History of psychology - Brazil. Scientific research - Psychology. Experimental psychology. Psychological phenomena and processes. Carolina Martuscelli Bori, 1924-2004.

Resumen: La Psicología en Brasil fue reconocida legalmente en 1962. Sin embargo, antes de este año, muchos profesionales han trabajado en la area. Carolina Martuscelli Bori ha sido considerado uno de estos profesionales y entre los aportes que hizo, su lucha por una mejor formación professional es una de las más citada. Este trabajo tuvo como objetivo conocer la contribución de Bori a partir sus artículos publicados hasta el año de 1962. Las busquedas a los artículos fueron efectuadas en las revistas Ciência e Cultura, Boletim de Psicologia y la Revista Brasileira de Psicologia, em su curriculum Lattes, em búsqueda em la biblioteca de la Universidade de São Paulo y en las referencias de los artículos escritos por la própria Carolina Bori. 19 artículos fueron localizados, de los quales ocho fueron publicados hasta 1962. El análisis permite afirmar que el trabajo de Carolina Bori presenta discusiones que pueden ayudar en el direccion y la preparacion en varios temas éticos y académicos actuales, como la investigación experimental em los cursos de pregrado, la metodologia científica, el desarrollo científico y la producción del conocimiento.

Palabras clave: Historia de la psicologia - Brasil. Investigación cientifica - Psicologia. Psicologia experimental. Fenômenos y procesos psicológicos. Carolina Martuscelli Bori, 1924-2004.

A Psicologia, no Brasil, teve seu reconhecimento legal no ano 1962, quando a Lei $\mathrm{n} \mathbf{0} 4119 / 62$ foi aprovada. Contudo, ter reconhecimento legal não significa dizer que a Psicologia no Brasil tenha começado em 1962. Autores como Massimi (1990) e Antunes (2004), por exemplo, analisaram obras de diversos profissionais que contribuíram para o desenvolvimento da área, no País, desde séculos atrás.

Dentre os profissionais que contribuíram para o desenvolvimento da Psicologia no Brasil, está Carolina Martuscelli Bori (1924-2004). Sua contribuição para o desenvolvimento científico no País tem sido apontada em diversas publicações. Em 1998, por exemplo, uma edição especial da revista Psicologia USP foi dedicada a ela. Pesquisadores de várias áreas assinaram artigos que relatam algum evento em que Carolina Bori teve colaboração indispensável e que descrevem sua militância na formação de docentes/pesquisadores, na implantação de cursos e laboratórios de Psicologia experimental, na introdução e na difusão da análise experimental do 
comportamento, na atuação em associações e órgãos de fomento e na divulgação da ciência, entre outras.

Quando de seu falecimento, outros artigos sobre ela foram publicados, e, em um deles, Kerbauy (2004) aponta cargos ocupados e atividades realizadas por Bori. A autora destacou os cargos que Bori ocupou em várias associações científicas nacionais e internacionais, os papéis importantes desempenhados por ela em várias universidades brasileiras e estrangeiras, a participação ativa em conselhos editoriais das revistas científicas e a tradução de obras como Principles of Psychology, de Keller e Schoenfeld (1950), Research in Behavior Modification, de Krasner e Ullmann (1965, 1972) e Methods in Social Research, de Gode e Hatt (1952).

Guedes, por sua vez, define a contribuição de Bori como memorável. Afirmou:

\begin{abstract}
Ninguém melhor que Carolina Bori para receber esse nome. Oitenta anos, dos quais mais de cinquenta batalhando pela Psicologia e pela educação (formou-se em Pedagogia pela USP em 1947) e pelo menos quarenta pela ciência brasileira (para citar apenas o período a partir do qual se dedicou decididamente à SBPC), Doutora Carolina é lembrada por colegas das muitas instituições pelas quais passou como "uma das personalidades reconhecidamente mais expressivas da Psicologia e da ciência brasileira“ (2004, p. 189)
\end{abstract}

Carolina Bori esteve, em grande parte de sua vida, vinculada à Universidade de São Paulo (USP). Graduou-se em Pedagogia, em 1947, especializou-se em Psicologia Educacional em 1948, pela USP, e, nesse mesmo ano, torna-se professora assistente dessa mesma universidade. Era professora também na USP quando se aposentou, contudo, sem nunca deixar de dar importantes contribuições para a ciência.
Antes de 1962, a Psicologia ainda não era uma profissão legalmente reconhecida no Brasil e não era ensinada nos cursos de graduação de Psicologia, como nos dias atuais. A primeira oferta de curso de graduação em Psicologia, na USP, foi em 1958. Até então, a Psicologia era uma disciplina que fazia parte do Curso de Filosofia e Pedagogia. Carolina Martuscelli Bori (no começo da década de 50, ainda Carolina Martuscelli) era professora assistente da cátedra de Annita Cabral, e dava aulas de Psicologia Experimental. Era grande conhecedora da obra de Kurt Lewin e, em suas aulas, fazia com que seus alunos replicassem pesquisas sob a influência teórica da Gestalt. Conforme relato de Arno Engelman, ex-aluno no ano 1955, as aulas que ela dava foram assim descritas: "Nas poucas aulas que assisti, parecia que era uma boa iniciação ao que se denomina Psicologia como ciência empírica. Além disso, e, para mim, era o primeiro contato com o tema psicofísica, uma das divisões de mensuração da Psicologia" (1998). Ainda para outro ex-aluno, Isaias Pessotti: "Para um dos experimentos de psicofísica, os alunos foram divididos em duplas. Cada uma devia fazer dois experimentos (um cada aluno) que confrontassem dois métodos da psicofísica clássica" (1998).

Também na década de 50 houve intensas discussões e lutas para o reconhecimento da Psicologia como profissão no Brasil. Carolina Bori foi uma, dentre outras pessoas, que participou ativamente em prol de tal reconhecimento, que daria a esse profissional o título de psicólogo, e não de psicologista (como queriam os médicos) (Baptista, 2010).

Quando, em 1954, foi fundada a Sociedade Brasileira de Psicologia (já extinta), foi Carolina Bori quem assumiu a presidência. Sem entrar em maiores detalhes sobre o que foi feito pela sociedade, em uma nota na revista Ciência e Cultura, há a seguinte afirmação sobre os objetivos da nova sociedade: "Em outubro, fundou-se, em São Paulo, a Sociedade 
Brasileira de Psicologia, que tem por objetivo o desenvolvimento da Psicologia como ciência, como profissão e como um meio de promover o bem-estar humano" (1954, p. 216). No mesmo ano em que Bori se associa à Sociedade Brasileira para o Progresso da Ciência (SBPC), essa mesma nota afirma que é intenção dos sócios da Sociedade Brasileira de Psicologia manter colaboração estreita com a SBPC.

Em 1956, Bori se vinculou ao Centro Brasileiro de Pesquisas Educacionais (CBPE), criado em 1955. Esse centro, idealizado por Lourenço Filho (1897-1970) e Anísio Teixeira (19001971), foi proposto para melhorar e cuidar da educação no Brasil. Para seus idealizadores, esse seria o caminho para se estabelecer uma sociedade mais organizada e politicamente mais forte (Ferreira, 2008). Organizado dentro da estrutura do Instituto Nacional de Estudos Pedagógicos (INEP), o CBPE foi “um importante estímulo ao desenvolvimento de pesquisas em ciências sociais sobre questões relacionadas à educação brasileira" (2008, p. 279).

Em abril de 1961, um novo curso começou a ser oferecido por Fred S. Keller, um professor norte-americano recém-chegado à USP. Até essa época, pouco se sabia sobre behaviorismo, análise do comportamento ou análise experimental do comportamento no Brasil (Keller, 1987). Alguns nomes que se tornaram importantes para a institucionalização da análise do comportamento no País estiveram presentes nesse curso, entre eles, Carolina Bori, então professora do Departamento de Psicologia da Universidade de São Paulo, que estava dirigindo o Departamento de Psicologia no curso de Pedagogia de Rio Claro. Ao fim desse mesmo ano, Keller voltou aos Estados Unidos, e, no ano seguinte, Gilmour Sherman, então professor da Barnard College (Columbia, EUA), veio ao Brasil e continuou as atividades em análise experimental do comportamento.
Em 1962, Darcy Ribeiro convidou Carolina Bori para elaborar e dar início ao Departamento de Psicologia da Universidade de Brasília $(U n B)$, na recente capital brasileira. Bori, por sua vez, estendeu o convite a Rodolfo Azzi, Gil Sherman e Keller. Esse projeto para o novo Departamento de Psicologia da UnB se mostrou revolucionário em vários aspectos, mas foi abruptamente interrompido em 1965, por intervenção do golpe militar brasileiro (Guedes, Cândido, Belloti, Giolo, Vieira, Matheus, Miguel, \& Gurgel, 2008; Keller, 1972; Keller, Bori, \& Azzi, 1964; Matos, 1998; Todorov, 1990, 2003, 2006).

Entre o final da década de 50 e o começo da década de 60, Carolina Bori foi professora de Psicologia no Departamento de Pedagogia da Faculdade de Filosofia, Ciências e Letras de Rio Claro, onde organizou e equipou um laboratório com o objetivo de servir para o ensino e a investigação de problemas da Psicologia, tanto por alunos quanto por professores (Bori, 1964). Nesse curso, também estavam os professores Isaias Pessotti e Geraldina Witter, e nele já se observa alguma influência das aulas de Keller. Havia, dentre os equipamentos do laboratório para estudos em psicofísica, uma caixa de condicionamento operante, conforme introduzido por Keller em suas aulas. Abaixo, segue o primeiro parágrafo do artigo que conta a experiência de Rio Claro:

Na organização e instalação de um laboratório que deve servir para o ensino e a investigação de problemas da Psicologia, coloca-se com uma certa relevância a questão dos aparelhos e instrumentos. O artigo que apresentamos tem por finalidade relatar a experiência que vimos realizando nos últimos quatro anos no Departamento de Psicologia da Faculdade de Filosofia, Ciências e Letras de Rio Claro, no sentido de equipar o laboratório de modo a permitir um bom nível de trabalho experimental para alunos e professores (Bori, 1964, p. 61)

Como se nota, há diversos trabalhos históricos que enfatizam o envolvimento políticocientífico de Bori, porém, o que pouco se 
conhece é sua produção bibliográfica. Seus artigos não são muito conhecidos nem citados. Assim, com este trabalho, busca-se analisar a contribuição teórica de Carolina Bori para a formação de psicólogos no Brasil. Para isso, serão analisados artigos publicados até o ano 1962.

\section{Publicações de Carolina Bori}

Para localizar os artigos publicados por Carolina Martuscelli Bori, foi realizada uma busca feita nas revistas Ciência e Cultura, Boletim de Psicologia e Jornal Brasileiro de Psicologia, no seu currículo Lattes, pela busca na biblioteca da USP e em referências de artigos escritos sobre a própria Carolina Bori.

Ao todo, 19 artigos foram localizados e divididos em dois períodos. O primeiro vai até 1961 , ano anterior ao do reconhecimento legal da Psicologia. O segundo período, que começa no ano 1962, não será abordado neste estudo, assim como os resumos de trabalhos apresentados em congressos.

Entre os temas discutidos em seus artigos, a formação do psicólogo é constante desde a segunda publicação localizada. O estudo da personalidade é outro tema muito discutido, e aparece até 1959, ano da última publicação no período em análise. Seu primeiro artigo publicado foi em 1950, sendo localizado um total de oito publicações nesse período. A partir de 1960, houve uma redução no número de publicações, localizando-se, até a data de sua morte, mais onze artigos. Grande parte deles, nesse segundo período, poderia ser categorizada como relato de experiência. Apenas como observação, em alguns momentos, a publicação é assinada com o nome Carolina Martuscelli (nome de solteira), e, em outros, com o nome Carolina Martuscelli Bori (nome de casada). Em nenhum dos artigos analisados foi encontrado um segundo autor.
Como a formação do psicólogo foi um tema comum nas atividades que Bori desenvolveu durante a década de 60 e em quase todos os artigos analisados a seguir, esse foi um aspecto que dirigiu a leitura dos textos e sua discussão. Todos os artigos analisados foram divididos em duas categorias, que enfatizam a experimentação como maneira de pensar ou o estudo dos fenômenos psicológicos.

\section{Formação do psicólogo: a experimentação como uma maneira de pensar}

Entre os temas abordados por Bori em seus artigos, a formação do psicólogo é constante. Em artigo publicado em 1954, por exemplo, ela escreve:

O desenvolvimento alcançado pela Psicologia exige do estudioso da matéria outros conhecimentos além daqueles que constam dos programas adotados. Neste artigo, limitaremos a consideração desse aspecto tão importante da formação do psicólogo, mencionando uma das matérias que deveriam ser conhecidas por todo estudante de Psicologia: a estatística (p. 18)

Nesse artigo, Bori parece criticar a formação dos profissionais que atuavam na Psicologia, quando diz que o estudioso da matéria precisa de conhecimentos que não constam nos programas de formação. Mesmo reconhecendo que existem muitos psicólogos que criticam o uso da estatística em problemas psicológicos, ela propõe sua inclusão na formação do psicólogo, discute as ênfases que precisam ser dadas e explica como essa área pode ser útil para o psicólogo. Na citação acima, observa-se uma preocupação em oferecer ao futuro psicólogo conhecimentos produzidos por outras áreas em vez de uma formação limitada ao conhecimento elaborado pelos próprios profissionais da área. Apesar de não especificar, nesse artigo, quais outras áreas do conhecimento considerava necessárias para 
a formação do futuro psicólogo, fica clara a importância que a estatística teria, na visão da autora. Para ela, há uma necessidade de formar profissionais que saibam criticar aquilo que leem, e, para isso, o conhecimento da estatística seria imprescindível. Sobre isso, Bori afirma:

Quer para realizar experimentos ou criticar experimentos feitos por outrem, o estudante de Psicologia (futuro psicólogo) deverá aprender quando e onde aplicar a estatística, a selecionar a técnica estatística adequada ao problema, a realizar os cálculos necessários e, ainda, não menos importante, a analisar e a interpretar os resultados estatísticos para poder traduzilos em termos de Psicologia (1954, p. 19)

Além da estatística, outro aspecto importante da formação do psicólogo deveria ser a experimentação. Para Bori, a experimentação seria uma atividade que todo aluno de Psicologia deveria desenvolver durante sua formação acadêmica, porque o desenvolvimento da própria Psicologia dela depende. Ao utilizar análises estatísticas em estudos experimentais, portanto, deve-se tomar o devido cuidado para que o foco seja dado ao objeto, e não ao método:

O estudante de Psicologia será levado a desenvolver uma atividade como experimentador. Essa atividade, da qual depende o desenvolvimento da própria ciência psicológica, requer o conhecimento e a prática de técnicas experimentais como de técnicas estatísticas (1954, p. 19)

O curso de estatística para psicólogos, conforme proposta de Bori, deveria ter, em linhas gerais, a) uma introdução esclarecendo a finalidade, os problemas e as limitações do uso de estatística a problemas psicológicos, b) a apresentação de meios para que os estudantes consigam organizar os resultados de pesquisa, de observação ou de experimento (preparar tabelas e gráficos, discutir suas finalidades), c) discussão de técnicas estatísticas para descrever situações, caracterizar grupos ou observações, incluindo médias e medidas de variabilidade e para descrever relações entre medidas através da noção de coeficiente de correlação, d) discussão de temas como amostra, representatividade de amostra, observações e cálculos estatísticos para verificação de hipóteses e e) verificação de significância.

Em quase todos os artigos escritos por Bori nesse período em análise, há, em algum momento, a defesa da experimentação, a citação de alguma pesquisa experimental como base para aplicação do conhecimento ou mesmo análises e defesas do método experimental. Tais defesas são feitas de forma clara e enfática em pelo menos três dos oito artigos analisados.

O primeiro, intitulado O Papel do Experimentador e do Sujeito na Situação Experimental, foi publicado em 1953. Nele, Carolina Bori discute o que é experimentação e laboratório, aborda as condições ideais para se fazer um experimento, a necessidade de controle de variáveis e as origens da experimentação em Psicologia. Assim, o tema é introduzido:

A experimentação é tanto uma maneira de pensar como um grupo de técnicas e precauções de laboratório. O laboratório é tradicionalmente considerado como uma situação de investigação na qual o estudo científico de um fenômeno pode se verificar sem a intervenção de fatores desconhecidos de qualquer magnitude.

Um experimento é simplesmente uma observação feita sob condições de controle (1953, p. 9)

Aqui começa-se a entender porque Bori considerava a experimentação um aspecto fundamental da formação do estudante: é maneira de pensar, que é ensinada conduzindo-se o aluno para um ambiente em que todos os fatores que podem influenciar o fenômeno estudado são conhecidos e controlados. Com essas condições 
Na análise de Bori, por volta de 1890, o uso do método experimental prometia à Psicologia um lugar entre as ciências naturais, o que dava mais dignidade à área. Com o passar dos anos, as opiniões sobre a eficácia dos experimentos foram divergindo: "enquanto alguns psicólogos

consideram os esforços não estritamente experimentais e de laboratório como fora do campo da ciência, outros dão à experimentação uma finalidade mais modesta" (1953, p. 11). estabelecidas, as observações são feitas, e, introduzindo-se as variáveis, uma a uma, seus efeitos são observados.

Segundo Bori, o procedimento básico em pesquisas experimentais é manter constantes todos os estímulos, exceto um. Este será manipulado e variará conforme a situação experimental. Caso o experimentador demonstre que a resposta de um indivíduo varia de modo sistemático em relação à variação desse único estímulo, é estabelecida a relação causal de um fenômeno psicológico.

Esse método teria tido grandes problemas desde as primeiras tentativas de usá-lo em assuntos psicológicos, porém, na opinião de Bori, "desde essa época, teve a Psicologia uma carreira vitoriosa" (1953, p. 10). Algumas dificuldades surgiram quando o método experimentado utilizado nas ciências mais antigas, como a Física e a fisiologia, passou a ser utilizado na Psicologia. Um deles foi respeitar os problemas e os conceitos peculiares da Psicologia; outro era realizar observações em condições de controle.

Na análise de Bori, por volta de 1890, o uso do método experimental prometia à Psicologia um lugar entre as ciências naturais, o que dava mais dignidade à área. Com o passar dos anos, as opiniões sobre a eficácia dos experimentos foram divergindo: "enquanto alguns psicólogos consideram os esforços não estritamente experimentais e de laboratório como fora do campo da ciência, outros dão à experimentação uma finalidade mais modesta" (1953, p. 11). Mas, na opinião da autora, "as observações que fornecem dados à Psicologia devem ser feitas o máximo possível sob condições controladas, isto é, devem ser experimentais".

Quanto ao modo de fazer observações em condições de controle de variáveis, Bori faz certa defesa da introspecção como método experimental, apesar de apontar algumas dificuldades em utilizá-la:

Há um tipo de experimento psicológico em que é a experiência consciente que deve ser estudada, e esta pode ser observada somente por aquele que a experimenta. Assim, o material é ao mesmo tempo $\mathbf{S}$ [sujeito] e observador, porque ele responde aos estímulos e também relata suas observações acerca de suas próprias respostas. Esse tipo de experimento segue a tradição de Titchener. Esses experimentos introspectivos têm importantes qualidades. O sujeito psicológico é somente uma parte do material experimental a ser manipulado. Existem também, pesos, luzes, instruções, etc., aos quais ele responde. Mas, por outro lado, ele não se limita a ser material experimental. Ele é também um "observador", o que quer dizer que ele tem uma das funções do $\mathbf{E}$ [experimentador].

Essa peculiaridade da introspecção torna difícil o controle das condições experimentais, pois há uma certa interrelação entre a aceita atitude de observação e a experiência a ser observada por ser o $\mathbf{S}$ ao mesmo tempo observador e observado (1953, p. 12)

É, porém, preciso acrescentar que a introspecção no sentido de auto-observação dos processos corporais permanece como uma parte necessária do método experimental, mas, como a observação de objetos, é incluída em técnicas e métodos experimentais mais gerais (1953, p. 13)

Para Bori, não demorou muito para que pesquisadores experimentais começassem a criticar o método introspectivo, mesmo tendo a sua utilização proporcionado progressos apreciáveis à área. Contudo, o descrédito na introspecção levou a outro problema: "uma importância exagerada ao método estatístico" (1953, p. 13).

Contudo, vale considerar que, para a autora, apenas com observações controladas não há uma contribuição científica de fato. Para tal, os resultados gerados pela observação em condições controladas devem ser interpretados com base no corpo teórico da área. Para que esses resultados sejam, 
de fato, uma contribuição científica, eles precisam ser comparados com resultados e teorias já apresentados até então:

Há ainda a considerar, porém, a interpretação crítica dos resultados, que traz em si a mais difícil e delicada de todas as funções do experimentador e dá à experimentação sua forma de contribuição científica, porque ela engloba os dados obtidos num todo coerente de conhecimentos comprovados (1953, p. 16)

O segundo trabalho em que Bori defende declaradamente a experimentação (Os Experimentos de Interrupção de Tarefa e a Teoria de Motivação de Kurt Lewin) foi concluído em 1953, mas publicado seis anos depois, em 1959. Esse trabalho, sua tese de doutorado, é de enorme densidade, quando comparado aos outros de sua autoria e ao contexto em que foi publicado. É um estudo sobre Psicologia experimental, tema que era quase inexistente no Brasil, ou mesmo em língua portuguesa ${ }^{1}$. Annita de Castilho e Marcondes Cabral (1959), catedrática da USP e orientadora desse trabalho, sintetiza esse fato na Apresentação:

Acreditamos haver interesse em sua publicação. A bibliografia psicológica em língua portuguesa, em outro nível que não o de compêndios ou obras de divulgação, é quase inexistente. Sobre Psicologia experimental, as publicações existentes contam-se a dedo.

Essa disciplina, de grande desenvolvimento primeiro na Alemanha e atualmente nos Estados Unidos, mais do que outros ramos da Psicologia, foi aqui descurada por ser o ensino da Psicologia no Brasil subsidiário ao de Filosofia ou Pedagogia.

Os primeiros parágrafos deste trabalho sintetizam claramente a posição de Bori quanto à experimentação. É uma profissional preocupada com os métodos utilizados na Psicologia, e visa a divulgar os avanços em relação ao método, à experimentação e aos conhecimentos produzidos pela Psicologia. Não se trata de uma defesa da ateorização da Psicologia, ou seja, da construção de uma Psicologia despreocupada com teorias, hipóteses, nem muito menos da Filosofia ou de qualquer outra forma de conhecimento. Trata-se de incluir a produção de um conhecimento sob condições rigorosas de controle experimental proporcionado pelo laboratório, como etapa necessária para a construção da ciência, como uma condição imprescindível. Para ela:

A Psicologia ampliou durante os últimos cem anos seu conteúdo, tornou cada vez mais rigoroso seu método científico, e ninguém lhe poderá negar hoje o lugar a que tem direito entre as demais ciências. Apesar das diferenças que existem entre os psicólogos, diferenças de interesse e orientação, todos estão de acordo em que a Psicologia só poderá ser considerada uma ciência na medida em que se basear na experimentação.

Nem a Psicologia, nem outra ciência qualquer pode prescindir da teoria. Mas essa teoria, para ser aceita, deve ser verificada pelo método experimental. O relevo dado a essa verificação como uma fase na construção da teoria evidencia uma maturidade crescente dos estudos psicológicos. As hipóteses são proposições que o psicólogo não deverá considerar como afirmações de fato, mas, ao contrário, como problemas de experimento (Martuscelli, 1959, p. 5)

Para ela, a expressão Psicologia Experimental não deveria denotar uma área independente da Psicologia; ao contrário, em toda produção de conhecimento em Psicologia, deveriam ser parte integrante as pesquisas realizadas sob condições controladas de laboratório. Desse modo, falhas nas conclusões das pesquisas não deveriam ser consideradas falhas no método, mas falhas nos arcabouço teórico que fundamenta a pesquisa, uma vez que os dados obtidos em uma pesquisa só têm algum valor quando analisados à luz de uma teoria. Um subsequente aprofundamento teórico auxiliará na elaboração de novas investigações. Essa é uma questão extremamente importante na definição de Psicologia feita por Bori. 
A qualidade de uma teoria deve ser avaliada em relação à possibilidade de se realizar pesquisas em condições controladas e de se fazer outras observações. Contudo, para Bori, "a teoria da psicologia contemporânea é notoriamente imprecisa" (1959, p. 6). Ainda assim, qualquer teoria que não permita a verificação da atividade psicológica humana é uma teoria psicológica falha. Para ela,

na medida em que a teoria se tornar mais refinada, poder-se-á esperar uma evolução correspondente de leis gerais abrangendo toda a atividade psicológica humana, leis essas verificadas, em cada um dos seus pontos, por experimentos. Nenhuma teoria psicológica deverá ter uma aceitação geral se não for fundamentada em provas tão rigorosas quanto as dos outros ramos do conhecimento científico.

A fecundidade científica de qualquer teoria é a sua capacidade de conduzir a experimentos produtivos e a outras observações, bem como a de levar a uma teoria mais satisfatória e ampla. $\mathrm{O}$ desenvolvimento científico da Psicologia não justifica hoje a aceitação entusiástica de uma orientação teórica cuja base experimental seja falha (1959, p. 6)

Nenhuma referência clara da visão de Bori sobre a utilidade prática da teoria e da pesquisa ou sobre a possibilidade de utilizar a teoria experimentalmente verificada (ou não) na resolução de problemas humanos foi encontrada nesse trabalho. Contudo, as pesquisas realizadas e analisadas por ela em sua tese estão inseridas em uma área da Psicologia conhecida como motivação, um assunto de extrema importância para a compreensão de problemas humanos. O que é discutido no texto (e que se relaciona com a aplicação a problemas humanos) é a origem do campo da motivação, e, aparentemente, ela dava uma importância fundamental à experimentação no que se refere à aplicação do conhecimento em Psicologia. Nas próprias palavras de Bori (1953),

A Psicologia experimental da motivação, produto dos últimos vinte e cinco anos, desenvolveu-se sob a pressão de interesses práticos representados por diferentes correntes da psiquiatria, como a psicanálise, e pelas ciências sociais. Essas influências diversas contribuíram visivelmente para a multiplicidade de seus conceitos e para a sua falta de unidade. A teoria nesse campo é fragmentária, e frequentemente deficiente nas suas generalizações (1959, p. 11)

Assim, a citação de Pavlov, na epígrafe do seu trabalho de doutorado, pode ser considerada representativa da posição de Bori em relação à ciência e à experimentação: "Aprendendo, experimentando, observando, procure não ficar na superfície dos fatos. Não se torne o arquivista dos fatos. Procure penetrar no segredo da sua ocorrência, persistentemente busque as leis que os governam".

A posição de Bori sobre experimentação em Psicologia está relacionada a uma posição em relação à definição do próprio campo da área. O conjunto de conceitos da disciplina, para ela, deveria permitir uma verificação pelo método experimental, mas, ao mesmo tempo, "não se trata somente de "criar" construções no gabinete, mas de verificar no laboratório quais são as construções adequadas" (1959, p. 18). Dois critérios deveriam direcionar todas as construções teóricas da Psicologia. No primeiro, os pesquisadores deveriam propor conceitos que tivessem propriedades lógico-matemáticas claras, e, no segundo, propor conceitos passíveis de definição operacional. Seguindo esses critérios, os psicólogos poderiam formular hipóteses de trabalho mais facilmente, além de poderem verificá-las experimentalmente.

Bori apresentou, em 1959, uma visão unificadora da Psicologia cujo crivo para aceitação de um conceito era a experimentação: "Se as construções provam ser úteis, afirma Lewin, elas não deveriam ser identificadas com um sistema particular de Psicologia, mas sim, tornar-se uma parte dos instrumentos do psicólogo em geral" (1959, 
p. 18). Contudo, ela propunha uma forma mais adequada de se fazer verificações experimentais:

\begin{abstract}
O método das construções é conhecido como método hipotético-dedutivo. Através desse método, todas as afirmações feitas na linguagem dos dados são traduzidas na linguagem das construções. Dessas construções, são derivadas as hipóteses de trabalho.

A abordagem hipotético-dedutiva, aliada a princípios matemáticos adequados, seria a mais válida para qualquer ciência que trata de questões de causalidade
\end{abstract}

Em 1957, Carolina Martuscelli Bori publicou o Estudo Psicológico do Grupo, trabalho realizado junto ao Centro Brasileiro de Pesquisas Educacionais (CBPE). Nesse artigo, ela propôs conhecer a personalidade de pessoas que faziam parte de uma certa seita religiosa em uma cidade do interior de Minas Gerais com o objetivo de levantar hipóteses que pudessem explicar uma série de comportamentos violentos que haviam ocorrido. Os métodos utilizados e os resultados encontrados pela autora serão melhor discutidos no tópico seguinte, contudo, aqui cabe comentar algumas comparações que fez nesse texto entre o método experimental e o método utilizado na pesquisa, denominado por ela pesquisa sociopsicológica:

Como é comum em toda pesquisa sóciopsicológica, a complexidade da situação torna a princípio impossível um ataque direto a um ou outro aspecto, que parece ser o mais importante. (...) Tudo que se pode esperar de um trabalho desse tipo é chegar o pesquisador a formar uma idéia das inter-relações estabelecidas, dos aspectos que poderão ser estudados diretamente mais tarde e do tipo de técnicas mais adequadas ao estudo.

Outro ponto a considerar é que, num trabalho dessa natureza, um "grupocontrole", no sentido experimental, não pode ser obtido. Os fatores que poderiam ser importantes e, portanto, deveriam ser objeto de verificação, não são conhecidos e nem sempre seriam prontamente controlados se se suspeitasse de sua existência e atuação. Partindo dessas considerações, o nosso estudo poderia ser caracterizado como sendo do tipo exploratório em oposição ao tipo de verificação de uma hipótese. Pelos resultados obtidos, poderemos chegar ao conhecimento de importantes relações entre variáveis, mas uma prova definitiva dessas relações só se poderá conseguir através de uma verificação das hipóteses (1957, p. 85)

Ao fazer essa afirmação, a autora havia abordado a possibilidade de controle de variáveis em estudos desse tipo. Para ela, a existência de um grupo-controle, como ocorre nas pesquisas experimentais, não pode ser obtido. Dessa forma, é impossível verificar a importância de variáveis ou mesmo controlálas, caso se suspeitasse de sua existência. De todo modo, esse tipo de pesquisa também traz importantes contribuições, como a formulação de hipóteses sobre relações de variáveis.

Assim, nesses artigos, percebe-se que, apesar da defesa de Bori sobre a importância da experimentação como parte da Psicologia, essa não é assumida como a única forma de construção de conhecimento na área. Além desse tipo de pesquisa, ela também publica outros artigos dotados de conteúdo histórico, conceitual e metodológico, mas reitera que o conhecimento produzido em laboratório, como se vê em algumas das citações acima, é a única forma de verificar hipóteses. Por isso, pelo fato de a experimentação ser parte essencial da Psicologia, ela deve ser parte da formação do psicólogo.

\section{O estudo de fenômenos psicológicos: fundamentando a formação do psicólogo}
A ênfase que Bori dá à experimentação não desvaloriza outras formas de produção de conhecimento sobre fenômenos psicológicos. Ela apresenta e discute a necessidade de adequar o método utilizado ao objeto em 
análise, como no artigo Estudo Psicológico do Grupo, discutido anteriormente. Mesmo com a defesa da abordagem experimental, nenhum dos artigos desse período é relato de pesquisa experimental. Bori publicou várias pesquisas conceituais, metodológicas ou que possuíam conteúdo histórico em diferentes temas da Psicologia, como a distância social, a percepção, a motivação e a personalidade. A autora apontou, ainda, algumas diferenças entre métodos de pesquisa, considerando a contribuição de cada um e discutiu a utilização de testes psicológicos para a construção do conhecimento e em contextos aplicados.

\section{a.1) Distância social}

O primeiro artigo localizado foi publicado por Bori (então Carolina Martuscelli) no ano 1950. Esse trabalho teve como objetivo "situar alguns aspectos do problema de aceitação de nacionalidades, grupos nacionais, 'raciais' e regionais ao nosso meio" (1950, p. 57). Para isso, a autora aplicou a Escala de Distância Social de Borgardus a 2076 estudantes da Universidade de São Paulo. Algumas modificações na escala original foram feitas no sentido de introduzir questões sobre distância social entre grupos regionais brasileiros. A escala original permitia analisar a aceitação de pessoas de outros países (grupos nacionais e raciais), como parentes por casamento, amigos, vizinhos, profissionais, cidadãos, turistas ou concluir se deveriam ser excluídos do país. Com as modificações propostas, essa mesma análise também poderia ser feita em relação aos grupos regionais paulistas, gaúchos, cariocas, baianos e nortistas.

Dentre os principais resultados dessa pesquisa, a autora afirma que praticamente todos os americanos e europeus, exceto os russos, são bem aceitos pelos paulistas. Além disso, percebeu que os dados dos universitários paulistas são mais igualitários e menos discriminativos do que os dos norte-americanos (dados esses usados para validação da escala original). Os dados apontam que há maior atitude negativa em relação aos judeus, seguidos pelos russos, japoneses, sírios, negros, armênios, mulatos, alemães, chineses, indus e norte-americanos (em ordem decrescente). Dentre os cinco grupos regionais incluídos na escala, os dados revelam uma preferência pelos próprios paulistas, seguidos dos gaúchos, cariocas, baianos e nortistas. Uma segunda análise verificou o grau de preconceito em relação a nível escolar, idade e sexo, não sendo encontrada nenhuma relação entre preconceito e nível escolar ou idade; porém, ao relacionar preconceito e sexo, percebeu uma diferença na nacionalidade de pessoas aceitas como parentes pelo casamento e das nacionalidades que deveriam ser excluídas do país. No primeiro caso, as mulheres foram mais preconceituosas; no segundo caso, os homens.

\section{a.2) Percepção e arte}

Em 1958, um pequeno artigo, considerado pela própria autora como "um breve resumo do assunto discutido", analisa o processo de criação artística a partir do desenvolvimento teórico da Psicologia em relação ao processo de percepção. Esse artigo não traz muitas informações, como os demais artigos de autoria de Bori aqui analisados. Entretanto, em uma passagem, pode-se perceber como a autora vê a possibilidade de utilizar o conhecimento científico em fenômenos psicológicos. O restante da discussão é um breve esboço sobre o conceito de percepção:

O desenvolvimento alcançado nos estudos do processo psicológico de percepção possibilita esclarecer e compreender como uma criação artística é percebida e como é realizada. $\mathrm{Na}$ aula, discutimos a aplicação do conhecimento do processo visual (especialmente o de percepção de forma), a relação entre a percepção visual e a representação que o artista faz do objeto 
que percebe e também a apreensão da representação resultante (1958, p. 103)

\section{a.3) Motivação}

Segundo Bori, a Psicologia experimental, no campo da motivação, apresentava-se, à época, fragmentada e sem unidade, apesar do grande desenvolvimento da área, produzido, principalmente, por investimentos e interesses práticos da psiquiatria e das ciências sociais. Para Bori, grande confusão conceitual e técnica caracterizava a Psicologia experimental no campo da motivação. Dessa forma, o objetivo da autora, em sua tese de doutoramento (concluída em 1953, mas publicada em 1959), foi apresentar a teoria de Kurt Lewin sobre o assunto, tema incomum dentro da teoria da Gestalt.

Uma crítica que a autora faz, baseada em Lewin, é que a Psicologia estuda "quase exclusivamente aquilo que é regular", desconsiderando os eventos que se apresentam como exceção. Isso caracterizaria uma ciência pré-galileica, que constrói conceitos de acordo com as discussões feitas por Aristóteles, em forma de classificações dicotômicas, sobre eventos frequentes e regulares. Mesmo com a introdução da estatística na Psicologia, não ocorreu nenhuma mudança em relação a essa característica. Pelo contrário, as técnicas estatísticas acentuaram as classificações dicotômicas.

Para Bori, um passo importante na introdução do modo de pensar galileico na Psicologia, considerando o caso individual sem elaborar conceitos valorativos e a interpretação por classificação, foi o estudo da "situação na qual se verifica o fato psicológico" (p.13), e isso é importante, porque muda a forma como a análise é feita. Desvia-se o olhar das classificações rígidas para as condições momentâneas, sejam elas do indivíduo, sejam da situação psicológica. Em suas palavras:
A tarefa que se apresenta à Psicologia seria, em última análise, procurar representar essa situação psicológica concreta com suas características individuais e com a estrutura concreta da pessoa (p. 14)

Para a autora, a Psicologia estaria passando por um momento de mudança nas propostas teóricas. Haveria uma necessidade de abandonar as classificações de comportamento porque, nas teorias tradicionais, são elas que determinam o comportamento de uma pessoa. $\mathrm{Na}$ proposta lewiniana, apresentada por Bori, a teoria de campo exigiria que o psicólogo respeitasse o caso individual e, ao mesmo tempo, englobasse leis gerais:

Essa situação de crise dentro da Psicologia evidenciaria a necessidade de uma teoria capaz de determinar as interrelações causais, de manter uma estreita relação com os fatos e de englobar, num único sistema, todas as contribuições esparsas dos vários ramos da Psicologia, representando tanto a lei geral quanto as características do caso individual. Uma teoria com tais peculiaridades só poderia ser construída abandonando qualquer tipo de classificação e tentando apresentar determinados conceitos (1959, p. 14)

Assim, Bori propôs que se analisasse uma série de experimentos realizados por Bluma Zeigarnik e seus seguidores, na qual os sujeitos eram colocados para realizar tarefas e, em algumas delas, o experimentador as interrompia quando o sujeito demonstrasse estar mais interessado. O que concluíram com essas pesquisas foi que as tarefas interrompidas foram as tarefas das quais os sujeitos mais se lembraram. Inúmeras replicações desse trabalho foram feitas, incluindo alteração na idade dos participantes, no tamanho do grupo, no choque emocional da interrupção e na memorização intencional das tarefas interrompidas, entre outros. Em todas as replicações, os mesmos resultados foram encontrados. Em relação à teoria, os autores das pesquisas analisadas afirmaram que a intenção de realizar uma tarefa equivale a um estado de tensão em uma pessoa. É a 
existência dessa tensão que gera a motivação para continuar uma tarefa. A interrupção da tarefa é um evento gerador de tensão, enquanto a eliminação da tensão é explicada pelo término da atividade ou pela passagem do tempo.

Apesar da extensa análise que Bori faz das pesquisas realizadas sobre interrupção de tarefas para explicar a motivação segundo a teoria de Lewin, a autora afirma haver uma série de problemas que precisam ser considerados. Um deles é o número de sujeitos utilizados, que não permite a realização de boas análises estatísticas, como Zeigarnik havia proposto. Além disso, a teoria de campo, de Lewin, não foi considerada nesse estudo, assim como outras discussões teóricas também não foram feitas para fundamentar as análises. As replicações que se seguiram ao trabalho original de Zeigarnik incluem inúmeras variáveis que interferem no efeito encontrado, o que coloca sérios problemas às conclusões de Zeigarnik, segundo Bori. Nas palavras da autora, "A falta de consistência dos resultados dos vários experimentos sobre interrupção de tarefas leva-nos a considerá-los como experimentos que possuem relativamente pequena precisão" (1959, p. 142).

Seguindo as críticas, Bori discute o conceito de motivação:

Toda vez que se fala de condições do organismo que dirigem o comportamento, está se fazendo referência à variável motivação. Essa variável é considerada como uma das mais importantes e, ao mesmo tempo, como fator mais complexo do comportamento. O termo motivação tornouse básico na Psicologia contemporânea (...) O termo motivação, como tal, é uma construção científica, isto é, no sentido comum, não é uma entidade ou coisa. É um processo hipotético ou estado do organismo inferido do comportamento deste (...)

A discussão de motivação é confusa, em parte porque a terminologia é frequentemente equívoca, e, em parte, porque a tradição tem um grande peso nesse campo, e é difícil encontrar um ponto de vista consistente. $\mathrm{O}$ conceito que dominou a cena no campo da motivação durante os últimos decênios é o conceito de instinto. Os psicólogos, levados a admitir que alguma coisa determina a resposta a uma situação e controla o curso das atividades mentais que intervêm entre a estimulação e a resposta, nomearam esse 'motor' da atividade: instinto (1959, pp. 146-147, grifo do próprio autor)

O ponto de vista da autora é uma clara crítica à construção e à elaboração do conceito de motivação. Esse conceito estaria sendo motivo de confusão entre os estudantes pela ausência de definições consistentes e pela multiplicidade de conceitos e vocabulários. Após as considerações acerca do conceito de motivação, Bori encerra seu texto com a seguinte crítica à teoria lewiniana: "Essa teoria apresentou um sistema de conceitos interessantes para a descrição do comportamento, mas os princípios dinâmicos especialmente introduzidos para explicar o comportamento não são satisfatoriamente esclarecidos" (1959, p. 155).

\section{a.4) O estudo da personalidade}

Outro tema comum entre os artigos de Carolina Bori é a personalidade, seja analisando seu estudo conceitual e experimental, seja o uso dos estudos sobre personalidade para análise e compreensão de fenômenos sociais.

Em 1955, publica O Desenho no Estudo da Personalidade: a Prova do Desenho da Figura Humana, artigo em que analisa o método desenvolvido por Karen Machover para o estudo da personalidade. Segundo a autora, as técnicas apresentadas por Machover estão baseadas na hipótese básica de que, ao desenhar, o indivíduo expressa amostras do comportamento mental e emocional, de acordo com a ideia de projeção e ajustamento. A posição de Bori em relação a essa forma de abordar a personalidade pode, aparentemente, ser resumida com a seguinte frase: "Muitas dessas técnicas (utilização de 
desenhos para o estudo da personalidade) se mostram inadequadas e insatisfatórias para o diagnóstico e orientação de tratamento" (1955, p. 60).

Tal inadequação se refere, segundo Bori, à pouca consideração teórica sobre como e em quais condições a projeção ocorre, uma vez que nem todo desenho da figura humana reflete aspectos conscientes e inconscientes da imagem do corpo do sujeito que o desenha. Outro problema dessa técnica é a interpretação, apenas, de características de forma e estrutura, de aspectos motor e expressivo. Segundo a autora, as linhas traçadas, as partes apagadas e o sombreado das figuras também deveriam ser considerados. Mesmo com tais críticas, é curioso perceber que, em 1957, quando realiza uma pesquisa em uma comunidade do interior do Estado de Minas Gerais, utiliza essa prova para estudar a personalidade dos indivíduos. A explicação para isso talvez possa ser dada quando se comparam os dois artigos.

A autora concorda com a ideia de que é possível a utilização de técnicas de desenho na elaboração de pesquisas. Pode-se considerar que Carolina Bori não via objeção quanto ao estudo dessa técnica em laboratório, em condições controladas, ou visando à construção de conhecimento. Pelo contrário, faz vários comentários sobre as contribuições desse método de estudo da personalidade, contudo, seu uso no contexto aplicado se mostra inadequado devido à falta de informações que traz acerca das causas dos fenômenos psicológicos, já se sabendo que, para Bori, deve-se buscar a relação entre eventos.

Em 1957, quando publica o estudo com a população de Catulé2, afirma ter o objetivo de "estudar o grupo de sujeitos do ponto de vista psicológico a fim de esclarecer ou pelo menos propor hipóteses para esclarecer o comportamento exteriorizado durante o período de duração dos acontecimentos" (p. 84). Na ocasião, estudou a personalidade de sujeitos que faziam parte de um determinado grupo de pessoas que havia aderido à religião adventista Promessa, e, por causa de uma série de comportamentos agressivos em que esse grupo se engajou, incluindo a morte de crianças, acabou sendo responsabilizado juridicamente. Tal evento mobilizou grande parte da mídia, da população brasileira e de estudiosos de fenômenos culturais. Ao estudar os acontecimentos desse grupo de pessoas que residiam na zona rural de uma cidade do interior de Minas Gerais, Bori deixa claro que não se trata de um estudo que tem como objetivo verificar hipóteses, mas buscar conhecer as possíveis inter-relações entre variáveis de aspectos que poderão ser estudados posteriormente, incluindo as técnicas utilizadas.

Apesar de ter apresentado algumas objeções quanto ao teste da figura humana para diagnosticar uma personalidade, Bori fez dele para fins de construção de conhecimento (Martuscelli, 1957), e, em uma sessão do artigo, confronta os dados obtidos pelas provas psicológicas aplicadas (prova de Rorschach e prova de Machover): "Verificamos que são significativamente semelhantes" (1957, p. 101). Além dos testes utilizados, a autora coletou dados a partir da discussão entre os indivíduos da comunidade, realizando, assim, uma análise do grupo e uma análise individual de algumas pessoas que foram consideradas mais relevantes para a compreensão das variáveis envolvidas no acontecido.

Ao analisar os dados, Bori observou grande desorganização socioeconômica, de difícil ajustamento, que não oferecia informações relevantes ou pontos de referência para a organização do campo psicológico aos seus sujeitos. Outro fator fundamental no ocorrido foi a característica individual. O grupo contava com pessoas passivas, com baixo nível de aspiração e alta "pobreza de vida interior", que podiam ser facilmente influenciadas pela situação. Assim, para a autora,

Em resumo, a análise individual dos sujeitos com um mínimo de iniciativa não altera o que foi acrescentado em relação ao grupo, 
e assim podemos concluir afirmando que o estudo psicológico indica ser esse um grupo de pessoas sem controles adequados que, num campo pobremente estruturado e diante da forte pressão do meio (no sentido de reajustamento), não conseguem ultrapassar os fatores derivados do campo e apresentam comportamentos que consideramos completamente anormais (1957, p. 117)

Em um terceiro artigo em que discute o estudo da personalidade (Bori, 1956), a autora faz um longo levantamento e análise e discussão de experimentos sobre a expressão da personalidade, remontando desde os gregos, como Aristóteles, com o estudo da fisiognomonia, e que perdurou até o século XVIII, quando começam a surgir estudos relacionados à fisiologia, com autores como Buffon e Camper. Bori apresenta Darwin, em seu A Expressão das Emoções nos Homens e Animais, como o grande sistematizador no estudo da expressão facial. Contudo, o grande revolucionário do campo de estudos da emoção teria sido, em sua opinião, William James, com a determinação das emoções pelas expressões, em vez de as expressões serem determinadas pelas emoções. A autora conclui afirmando que, apesar de pesquisas interessantes que apontam resultados significativos e proveitosos na abordagem do problema da personalidade, há a necessidade de mais estudos controlados, e que toda tentativa de entender a personalidade representa uma contribuição ao estudo desse complexo problema.

Segundo sua análise, os estudos da personalidade têm tomado duas direções. Uma delas é a direção de uma abordagem clínica, cujo objetivo primário é a aplicação prática e a utilização de técnicas. O estudo ou o estabelecimento de relações entre fenômenos são preocupações secundárias. Os dados obtidos são resultados de provas, informações obtidas das mais variadas fontes (por exemplo, assistentes sociais, entrevistas com o próprio paciente) e de outras indicações fornecidas pelo próprio comportamento do paciente. Esses são as fontes de dados de textos com preocupação aplicada que Bori analisou. Para ela, os artigos não tem referência bibliográfica e os dados são sintetizados intuitivamente e interpretados.

De outro lado, a abordagem experimental (segundo o caminho tomado pelas investigações da personalidade) não tem apresentado experimentos psicológicos úteis para o clínico. Na opinião de Bori, o problema é que o método experimental tem sido incorretamente aplicado: "O que é preciso é um estudo que tente padronizar não aspectos isolados, mas padrões complexos de cada um dos modos de expressão" (1956, p. 23).

\section{Considerações finais}

A partir da leitura dos artigos de Carolina Bori publicados até o ano 1962, chama a atenção sua consistência teórica e a elaboração de suas ideias. Seus artigos são claros, possuem embasamento teórico consistente, citam diversos autores, das mais variadas datas e áreas do conhecimento. Além disso, Bori demonstra conhecer tanto trabalhos teóricos quanto conceituais, metodológicos e experimentais. Não foi localizado nenhum trabalho de intervenção nem experimental (apesar da defesa que faz ao método).

As informações analisadas indicam que havia, na Universidade de São Paulo da década de 50, uma preocupação com a experimentação em Psicologia. Nas disciplinas que Carolina Bori lecionava, por exemplo, todos os alunos eram levados a realizar pesquisas, na maioria sobre psicofísica e de orientação lewiniana. Não apenas na Universidade de São Paulo, a pesquisa experimental em Psicologia foi um método de pesquisa defendido por Bori também na Faculdade de Filosofia Ciências e Letras de Rio Claro. Além do método experimental, outros métodos de pesquisa foram utilizados por Bori durante a década de 1950, principalmente durante sua atuação no Centro Brasileiro de Pesquisas Educacionais, o que pode ser considerado como a posição de Bori em relação ao desenvolvimento científico. 
Pode-se destacar, também, a preocupação de Carolina Bori com os aspectos educacionais e de formação do psicólogo, seja na luta pelo reconhecimento da área, seja no desenvolvimento das pesquisas junto ao Centro Brasileiro de Pesquisas Educacionais, seja na realização e na replicação de pesquisas junto aos alunos de graduação ou na discussão que faz sobre formação do psicólogo.

Assim, acredita-se que esta seja uma importante contribuição para a Psicologia no Brasil por analisar parte da obra de uma importante psicóloga brasileira. Muitas avaliações pessoais sobre ela foram feitas, considerando o seu envolvimento nos mais diversos cargos e funções exercidos. Contudo, sua produção escrita deixada nas bibliotecas ainda não havia sido reunida e analisada. Apesar de um número relativamente pequeno de artigos, se comparado às exigências atuais dos órgãos que avaliam a produtividade de um pesquisador, a obra de Carolina Bori apresenta discussões que podem auxiliar na elaboração e no direcionamento de várias questões éticas e acadêmicas atuais, como a pesquisa experimental em cursos de graduação, a metodologia científica, o desenvolvimento científico e a produção do conhecimento. 


\section{Gabriel Vieira Cândido}

Mestrado em Psicologia Experimental, docente do curso de psicologia da Universidade do Oeste Paulista, São Paulo, SP - Brasil.

E-mail: gabrielcandido@unoeste.br

\section{Marina Massimi}

Pós-doutorado pela Universidade de Coimbra. Professora Titular da Universidade de São Paulo, São Paulo SP - Brasil.

E-mail: mmarina@ffclrp.usp.br

Endereço para envio de correspondência:

CEUP, Psicologia, B3, Campus II da Universidade do Oeste Paulista Rodovia Raposo Tavares, Km 572 - Bairro Limoeiro Pres. Prudente - SP - Brasil

Cep: 19.067-175 


\section{Referências}

Antunes, M. A. M. (2004). A psicologia no Brasil no século XX desenvolvimento científico e profissional. In M. Massimi \& M. C. Guedes, História da psicologia no Brasil: novos estudos. (pp. 109-152). São Paulo: EDUC/Cortez.

Baptista, M. T. D. S. (2010). A regulamentação da profissão psicologia: documentos que explicitam o processo histórico. Psicologia: Ciência e Profissão, 30, 170-191.

Bori, C. M (1953). O papel do experimentador e do sujeito na situação experimental. Boletim de Psicologia, 5, 9-17.

Bori, C. M. (1954). Um curso de estatística aplicada à experimentação psicológica. Ciência e Cultura, 18, 19, 20, $18-21$.

Bori, C. M. (1956). Como o laboratório de psicologia estuda a expressão da personalidade. Boletim de Psicologia, 25, 26 e 27, 7-26.

Bori, C. M., (1964). Aparelhos e o laboratório de psicologia. Jornal Brasileiro de Psicologia, 1(1), 61-65.

Cabral, A. C. M. (1959). Apresentação. Em: Martuscelli, C. (1959). Experimentos de interrupção de tarefas e a teoria de motivação de Kurt Lewin. Tese doutorado. Universidade de São Paulo, SP.

Engelmann, A. (1998). Carolina Martuscelli Bori. Psicologia USP $9(1), 61-65$.

Ferreira, M. S. (2008). Os centros de pesquisas educacionais do INEP e os estudos em ciências sociais sobre a educação no Brasil. Revista Brasileira de Educação, 13(38), 279-411.

Gode, W. J., \& Hatt, P. K.. (1952). Methods in social research. Auckland: McGraw-Hill

Guedes, M. C. (2004). Memorável Carolina Martuscelli Bori (1924-2004). Memorandum, 7, 189-185

Guedes, M. C., Cândido, G. V., Belloti, A. C., Giolo, J. C. C., Vieira, M. C., Matheus, N. M., Miguel, R. R., \& Gurgel, T. A. (2008). A introdução da análise do comportamento no Brasil: vicissitudes. Behaviors, 12, 41-57.

Keller, F. S. (1972). Adeus, mestre! Ciência e Cultura, 24, 207-217.

Keller, F. S. (1987). Itens de um fichário. In Anais do XVII Encontro Anual da Sociedade de Psicologia. Ribeirão Preto, SP: Sociedade Brasileira de Psicologia.

Keller, F. S., Bori, C. M., \& Azzi, R. (1964). Um curso moderno de psicologia. Ciência e Cultura, 16, 387-399.

Keller, F. S., \& Schoenfeld, W. N. (1950). Principles of Psychology. East Norwalk, CT, US: Appleton-Century-Crofts.
Kerbauy, R. R. (2004). A presença de Carolina Martuscelli Bori na Psicologia. Revista Brasileira de Terapia Comportamental e Cognitiva, 6(2), 159-164.

Krasner L. \& Ullmann L. P., (Eds.) (1965). Research in behavior modification: new developments and implications. New York: Holt, Rinehart \& Winston.

Krasner, L., \& Ullmann, L. P. (Orgs.). Pesquisas Sobre Modificação de Comportamento, (C. M. Bori, trad.). São Paulo: Herder. (trabalho original publicado em 1966)

Massimi, M. (1990). História da psicologia brasileira: da época colonial até 1934.São Paulo: EPU.

Martuscelli, C. (1950). Uma pesquisa sobre aceitação de grupos nacionais, "raciais" e regionais em São Paulo. Boletim CXIX, Psicologia, 3. São Paulo: Universidade de São Paulo, Faculdade de Filosofia, Ciências e Letras.

Martuscelli, C. (1955). Desenho no estudo da personalidade: a prova de desenho da figura humana. Boletim de Psicologia, 21, 22, 23 e 24, 59-62.

Martuscelli, C. Estudo psicológico do grupo. In: Queiroz, M. I. P., Castaldi,C., Ribeiro, E. T., Martuscelli, C. (1957) Estudos de sociologia e história. São Paulo: Ed. Anhembi, pp. 84-125

Martuscelli, C. (1958). Percepção e arte. Boletim de Psicologia, 35 e $36,101$.

Martuscelli, C. (1959). Experimentos de interrupção de tarefas e a teoria de motivação de Kurt Lewin. Tese doutorado. Universidade de São Paulo, SP.

Matos, M. A. (1998). Contingências para a análise do comportamento no Brasil. Psicologia USP, 9(1), 89-100.

Pessotti, I. (1998). Minha chefe, Dona Carolina. Psicologia USP, 9(1), 243-246.

Sociedade Brasileira para o Progresso da Ciência. (1954). Sociedade Brasileira de Psicologia. Ciência e Cultura, 6(4), 216.

Todorov, J. C. (1990). The K \& S in Brazil. Journal of the Experimental Behavior Analysis, 54, 151-152.

Todorov, J. C. (2003). Science and human behavior. (Ciência e Comportamento Humano). Journal of the Experimental Behavior Analysis, 80, 341-343.

Todorov, J. C. (2006). Behavior analysis in Brazil. Avances en Psicología Latinoamericana, 24, 29-36. 